\title{
Anatomical trainer for bronchoscopy
}

\author{
Ranceviene D., Montvilaite A., Jakubauskaite R., Macas A.
}

The Department of Anaesthesiology, Lithuanian University of Health Sciences, Kaunas, Lithuania

\section{BACKGROUND}

Commercial trainers for bronchoscopy are useful for acquiring psychomotor skills, dexterity and eye-hand coordination, but the cost is a limiting factor of accessibility there. Our aim was to make a real-size anatomical model of tracheobronchial tree and investigate it's suitability for FOB training.

\section{MATERIALS AND METHODS}

A model of tracheobronchial tree was made based on anatomy textbooks and article by S. Di Domenico ${ }^{1}$ from wire, paper, glue and paint using papiermâché technique (Fig. 1 - 5). Photos of the trachea, carina and right bronchus were made during the $F O B$ and put next to a real human bronchoscopy photos (Fig. 6). 54 medical students (S) performed FOB on our model and on commercial trainer after the lecture. 8 certified anaesthesiologists - experts (E) and the same students took the semistructured interview about our made model. Differences between FOB duration on both trainers were measured by the Wilcoxon signed ranks test at $\mathrm{p}<0.05$.
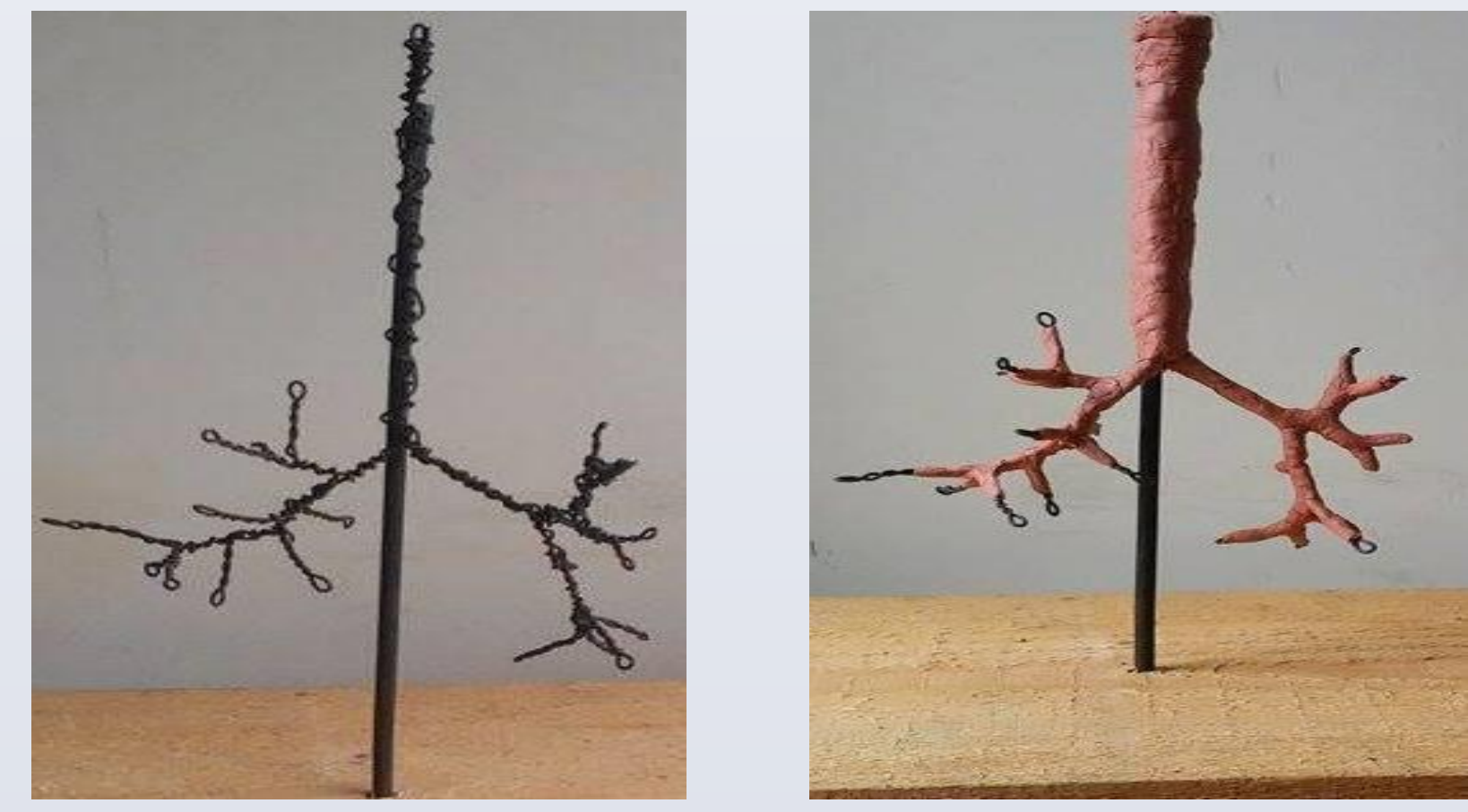

Figure 1. Wire framework.

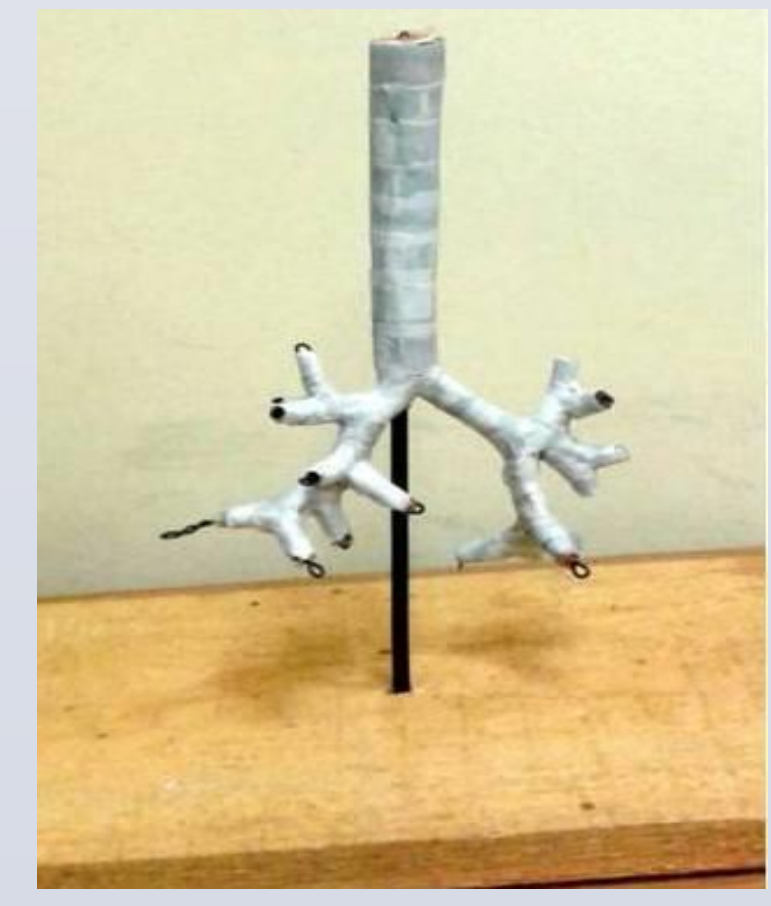

Figure 3. Papier-mâché technique.

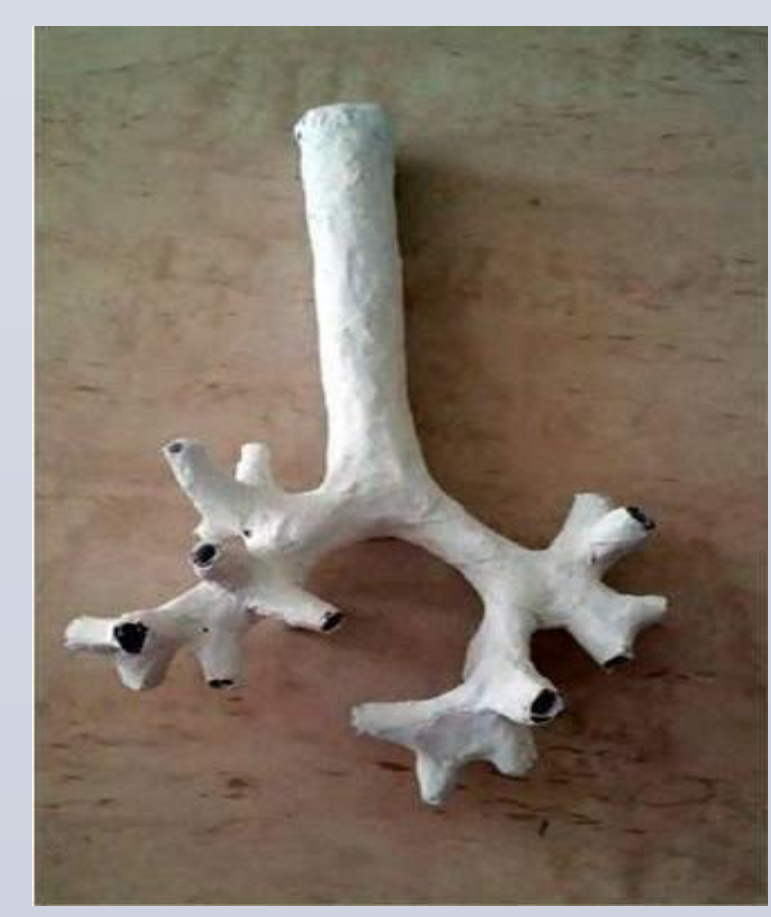

Figure 4. Removal from the carcass.

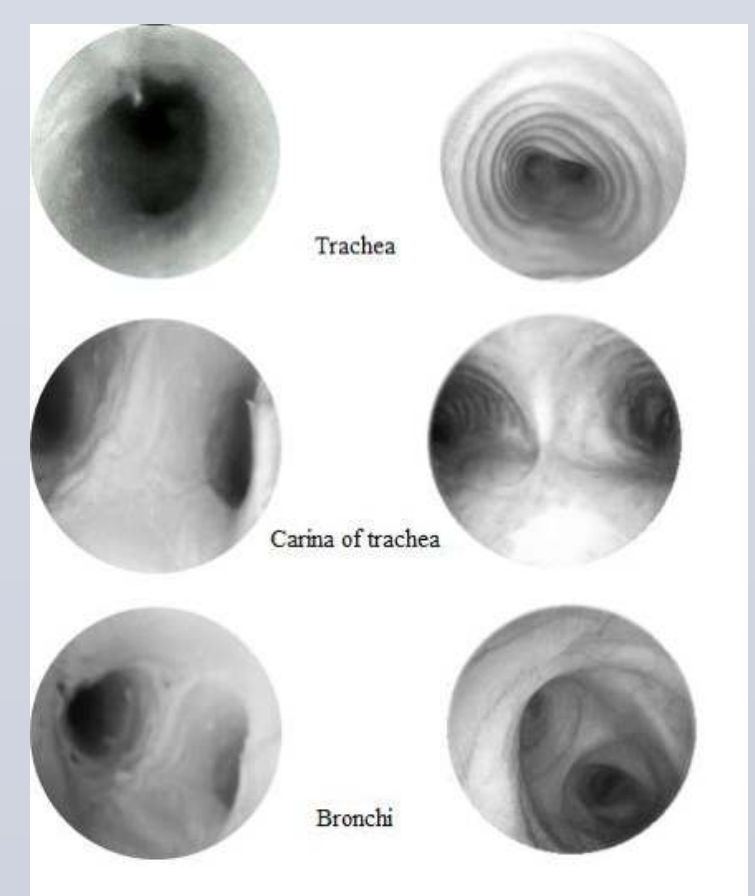

Figure 6. Model (L), human anatomy (R).

\section{RESULTS AND DISCUSSION}

Almost all answers (E 8, 100\%, S 49, 91\%) concerning the similarity between the model and real human anatomy (in photos) were "completely similar" and "similar". E (8, 100\%) and S (54,100\%) agreed that anatomical models are necessary for training and would be worth the time spent while making them. $1(12.5 \%)$ E preferred models to be manufactured and stated that making models are beneficial only for students who make them. 3 (37.5) E, $31(58.5 \%) S$ thought that it would be good for practising and gaining motor skills because of unlimited practice time. 1 (12.5\%) E and 13 (24.5\%) S emphasized low economical expenses. On the other hand, 1 (12.5\%) E and $14(26.4 \%) \mathrm{S}$ stated that such model might be short-lived. Others were concerned that colour and texture, lack of cartilage rings might reduce resemblance to real anatomy (E 2, 24.5\%, S 19, 35.8\%).

The duration of FOB on commercial model was $7-176 \mathrm{~s}$, mean $50.1 \pm 30.01$ $\mathrm{s}$, median $44.0 \mathrm{~s}$ mode $33.0 \mathrm{~s} .1(1.9 \%) \mathrm{S}$ did not complete the task. There was no significant difference in the duration of FOB between the models $(p=0.322)$.

Diagram 1. Semi-structured interview.

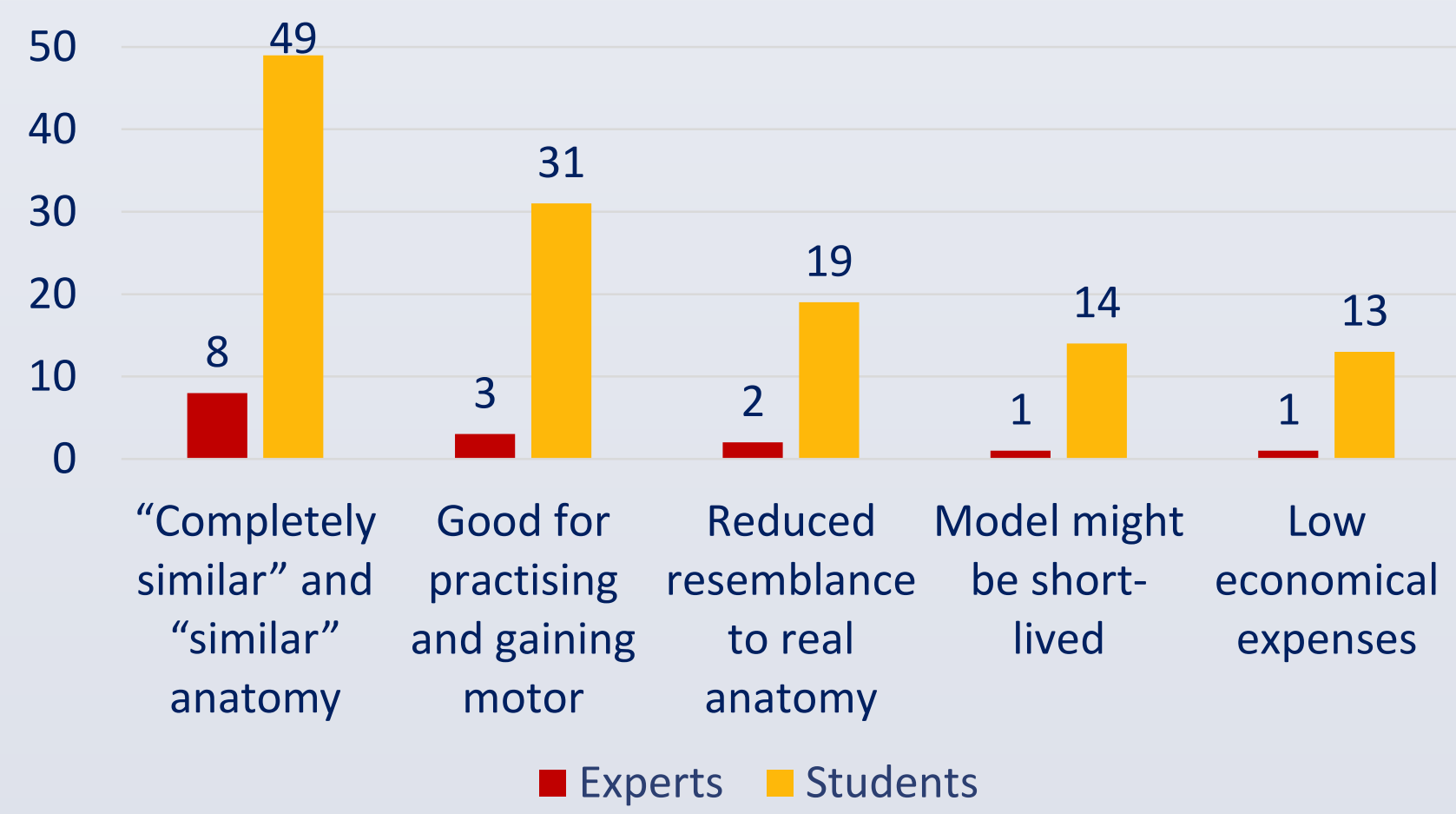

Table 1. Duration of FOB.

\begin{tabular}{c|c|c|c|c} 
Model & $\begin{array}{c}\text { The } \\
\text { duration of } \\
\text { FOB }\end{array}$ & $\begin{array}{c}\text { Mean } \pm \\
\text { standart } \\
\text { deviaton }\end{array}$ & Median & Mode \\
\hline $\begin{array}{c}\text { Students } \\
\text { model }\end{array}$ & $7-384 \mathrm{~s}$ & $51,5 \pm 62.98 \mathrm{~s}$ & $27,0 \mathrm{~s}$ & $18,0 \mathrm{~s}$ \\
\hline $\begin{array}{c}\text { Commercial } \\
\text { model }\end{array}$ & $7-176 \mathrm{~s}$ & $50,1 \pm 30,01$ & $44,0 \mathrm{~s}$ & $33,0 \mathrm{~s}$
\end{tabular}

\section{CONCLUSIONS}

Our model was anatomically correct and made from cheap materials. The duration of FOB was not significantly different between our model and commercial one.

\section{REFERENCES}

Domenico SD et all. Inexpensive anatomical trainer for bronchoscopy. ICVTS. 2007 Jun; 567-569. 